\title{
Genetic diversity of the tropical tree Terminalia amazonia (Combretaceae) in naturally fragmented populations
}

\author{
R Pither ${ }^{1}$, JS Shore ${ }^{2}$ and M Kellman ${ }^{1}$ \\ ${ }^{1}$ Department of Geography, York University, Toronto, Canada M3J 1P3; 'Department of Biology, York University, Toronto, \\ Canada M3J 1 P3
}

\begin{abstract}
The effect of long-term fragmentation on the genetic diversity of populations of the neotropical tree species, Terminalia amazonia, was studied using random amplified polymorphic DNA (RAPD) analysis. Leaf material from 104 trees was collected from three naturally fragmented gallery forest patches and three plots in nearby continuous forest in the Mountain Pine Ridge, Belize. In total, 30 RAPD bands generated by five decamer primers were used to compare the genetic diversity of the six populations in the two groups. Genetic variation within the populations $\left(H_{0}\right)$, as estimated by the Shannon diversity index, ranged from 0.32 to 0.38 , with an overall diversity of $0.38\left(H_{\text {species }}\right)$. Analysis of molecular variation revealed that most $(94.4 \%, P<0.001)$ of the
\end{abstract}

variation was attributable to differences among individuals within populations. Population differentiation was significantly $(P=0.038)$ lower among the fragmented populations than among continuous forest populations. On average, the fragmented populations also had slightly, but statistically significant $(P=0.046)$ lower levels of genetic diversity. However, one gallery forest site had a higher level of genetic diversity than two of the continuous forest sites. We suggest that the long-term effect of fragmentation on the genetic diversity of tropical trees will depend upon the amount of local forest cover in proximity to the fragmented populations. Heredity (2003) 91, 307-313. doi:10.1038/sj.hdy.6800299

Keywords: conservation genetics; forest fragmentation; gallery forest; genetic diversity; RAPD; tropical trees; gene flow

\section{Introduction}

Tropical rainforests are the most biologically diverse terrestrial ecosystems, but much of this diversity is under threat from extensive forest loss and fragmentation (Myers, 1986). The threat lies not only in the outright loss of species, but also in the potential loss of genetic diversity and fitness of remnant populations. The maintenance of genetic variation is considered essential for the long-term survival of a species since genetic diversity provides a species' evolutionary potential (Frankel and Soulé, 1981). Furthermore, a reduction in diversity through the loss of alleles reduces a population's ability to respond to biotic challenges (eg, pathogens) and to changes in the abiotic environment.

Forest loss and fragmentation alters the composition, configuration, and connectivity of the landscape (Taylor et al, 1993). These changes can affect genetic diversity in several ways: through the direct loss of genotypes as habitats and its residents are extinguished, through processes related to reduced population sizes, and through the isolation of remnant populations, which can modify and limit gene flow (White et al, 2002). Such impacts can lead to genetic bottlenecks, increased random genetic drift, and inbreeding depression, which can ultimately result in a loss of genetic variation

Correspondence: $R$ Pither, 635 MacLaren St, Ottawa, Ont, Canada, K1R 5L1. E-mail: richpither@yahoo.ca

Received 5 August 2002; accepted 25 February 2003 and increased genetic differentiation between remnant populations (Young et al, 1996).

Thus far there have been only a few studies that have assessed the impact of forest fragmentation on the genetic diversity of tropical tree species. For example, in Costa Rica, allozyme analysis revealed that small, isolated populations of the canopy tree Pithecellobium elegans in remnant forests had suffered genetic erosion (Hall et al, 1996). In the same region, fragmented populations of Carapa guianensis had lower allelic diversity as a result of restricted gene flow, although there was no evidence of inbreeding in saplings (Dayanadan et al, 1999). Evidence of significant inbreeding was found in seedlings of Symphonia globulifera, resulting in significant genetic differentiation among fragmented forest populations (Aldrich et al, 1998). However, the low density, canopy emergent Dinizia excelsa was found to thrive in forest fragments and as isolated individuals in pastures in Amazonia, thanks to pollination by the nonnative African honeybee (Dick, 2001). And although fragmentation of a tropical dry forest in Honduras led to the loss of some low-frequency microsatellite alleles in Swietenia humilis, White et al (2002) observed increased pollen flow among fragmented populations, which they hypothesized could eventually restore and augment levels of genetic variation.

Most of the studies mentioned were conducted in landscapes in which forest fragmentation was a relatively recent event. Consequently, the adult trees within the forest remnants would predate fragmentation and 
ecological processes would not have had sufficient time to adjust to the modified environment. Even when seedlings are analysed rather than adults, one cannot be sure whether the genetic diversity of the seedling cohort can be used to predict the future diversity of the remnant population (Hamrick et al, 1993; Aldrich et al, 1998; Condit et al, 1998). Thus, the conditions in relatively young forest fragments may be a poor indicator of the long-term genetic consequences of fragmentation. Instead, an alternative approach would be to use natural fragments, such as gallery forests within savannas (Pither and Kellman, 2002). These types of forests may be many centuries old, which means sufficient time would have passed to allow for the turnover of at least a few generations of trees and for landscape processes to have adjusted to the altered landscape (Kellman, 1996).

This paper presents results from a study on the genetic diversity of the tropical tree Terminalia amazonia (Combretaceae) in gallery forests of the Mountain Pine Ridge (MPR) savanna, Belize. In the continuous forests surrounding the MPR, T. amazonia is very common but in the naturally fragmented gallery forests within savanna, it is present at much lower densities. The objectives of the study were to determine whether long-term fragmentation had led to a loss of genetic variation within gallery forests and to increased genetic differentiation among populations. Random amplified polymorphic DNA (RAPD) analysis was used to compare populations from three gallery forests to populations from three plots within nearby continuous forests. This study is a component of a larger project whose purpose is to determine whether a network of very small forest fragments can contribute to the maintenance of regional diversity in human-dominated landscapes (Pither and Kellman, 2002).

\section{Materials and methods}

\section{Study area}

Research was conducted in the Mountain Pine Ridge in Belize, Central America $\left(17^{\circ} \mathrm{N}, 88^{\circ} \mathrm{W}\right)$. Although surrounded by continuous broad-leaved forest, the MPR itself is dominated by a pine savanna. Within the savanna is a naturally fragmented network of broadleaved gallery forests (Figure 1). Previous work has determined that the gallery forests contain levels of plant diversity comparable to that found in regional continuous forests at local scales (Meave and Kellman, 1994). High levels of tree diversity were also found within the smaller micro-forests (less than 1 ha in size) and tree thickets (linear riparian forests less than $20 \mathrm{~m}$ in width) that can be found scattered along creeks throughout the MPR (Pither and Kellman, 2002).

Charcoal and pollen evidence suggest that the savanna has been in existence for at least 11000 years and is likely to be a remnant of a system of larger savannas that were present throughout Central America during the last Glacial Maximum (Kellman, 1989). Given that the MPR savanna has existed for thousands of years, it is likely that gallery forests have been present throughout the same time period (Meave and Kellman, 1994). It is also probable that the amount of forested area is dynamic increasing or decreasing depending on fluctuations in climate and fire frequencies. The three gallery forest (GF)

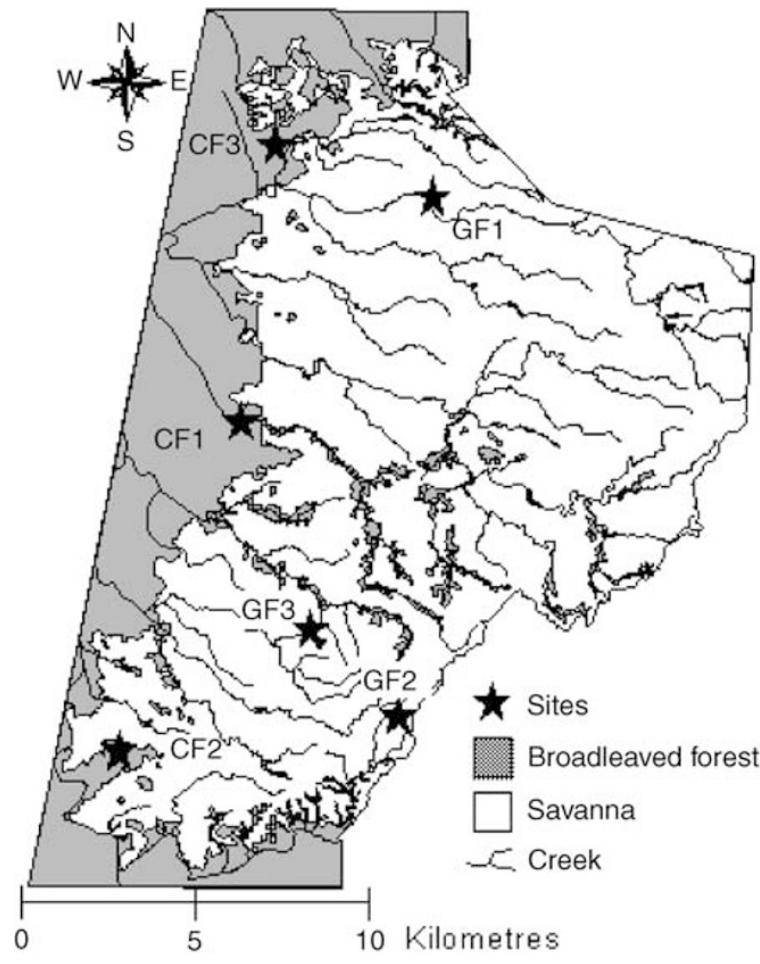

Figure 1 Gallery and continuous forest sites in the western section of the Mountain Pine Ridge, Belize.

sites used in this study all possessed characteristics that we assume are indicative of very old forests: welldeveloped canopies, very large trees, and the presence of tree species not normally found in recently established forests. All GF sites were smaller than 1 ha in size (Table 1) and approximately $4 \mathrm{~km}$ from continuous forest but within $2 \mathrm{~km}$ of networks of larger GF (Figure 1). Three control plots were located along creeks in the nearby continuous forest $(\mathrm{CF})$.

\section{Species description}

T. amazonia (Combretaceae) is a common large tree found throughout much of the neotropics (Standley, 1962). Little is known about its reproductive biology but most species in the genus are outcrossing despite being hermaphroditic (Srivastav et al, 1993). T. amazonia is pollinated by insects and its seeds are dispersed by wind (Gentry, 1993). It grows in lowlands and uplands and is both a commercial timber species, and a native tree favoured for reforestation projects. Although reports indicate that the species can apparently grow in savanna, this is not the case in the MPR, where extensive reconnaissance determined that it is restricted to forests with closed canopies. In fact, Terminalia seeds failed to germinate during a seed planting experiment in the MPR savanna (Kellman and Miyanishi, 1982). Within the continuous forest surrounding the MPR, T. amazonia is a very common tree species (approximately 29 adults/ ha, Table 1) but within GF it exists in much lower densities (approximately 11 adults/ha). Like several other hardwood species, $T$. amazonia was selectively logged many years ago in the continuous forests of the MPR but it is highly unlikely that the relatively remote 
Table 1 Summary of site information: size of plot or forest, density of adults ( $\geq 5 \mathrm{~cm} \mathrm{dbh}$ ) and number of individuals (adults+juveniles) of Terminalia amazonia analysed from study sites in the Mountain Pine Ridge, Belize

\begin{tabular}{lcccc}
\hline Forest type & Site & $\begin{array}{c}\text { Size of plot } \\
\text { or forest (ha) }\end{array}$ & $\begin{array}{c}\text { Density } \\
\text { (adults/ha) }\end{array}$ & $\begin{array}{c}\text { No. of trees } \\
\text { analysed }\end{array}$ \\
\hline Continuous forest & CF1 & 1 & 28.1 & 17 \\
& CF2 & 1 & 35.7 & 17 \\
& CF3 & 1 & 23.3 & 18 \\
Gallery forest & GF1 & 0.75 & 12.3 & 15 \\
& GF2 & 0.35 & 11.6 & 17 \\
& GF3 & 0.89 & 9.0 & 20 \\
Total & & & & 104 \\
\hline
\end{tabular}

gallery forest sites used in this study were subjected to logging. Ohri (1996) reported that there is considerable variation in chromosome size and polyploidy level among species of the pantropical genus Terminalia. However, we did not find any published reports with data on the genetics of the species T. amazonia.

\section{Sampling}

Field work was conducted over a 3-week period in August, 2000. Leaf material was collected from all adults $(\geq 5 \mathrm{~cm} \mathrm{dbh}$ ) and some juveniles ( $>1 \mathrm{~m}$ in height) within the three GF sites. Collection of leaf material in continuous forest was restricted to plots of approximately 1 ha (to correspond to the small size of the GF) and to individuals at least $10 \mathrm{~m}$ apart. Young leaves were collected when possible. All leaves were stored in individual containers with labels and at the end of the day deposited in liquid nitrogen. Upon return to Toronto, Canada, the collection was stored in a deep freezer at $-80^{\circ} \mathrm{C}$

\section{Laboratory procedures}

DNA was extracted from frozen leaf material using the CTAB technique (Doyle and Doyle, 1987) and further purified using the Wizard ${ }^{\circledR}$ DNA Clean-up kit (Promega). PCR amplification solutions $(25 \mu \mathrm{l})$ included approximately $5-10 \mathrm{ng}$ of genomic DNA, $1.5 \mathrm{mM} \mathrm{MgCl}_{2}$, $200 \mu \mathrm{M}$ of each dNTP, $1 \mathrm{U}$ of Tsg DNA Polymerase and reaction buffer (BioBasic Inc), and $1 \mu \mathrm{M}$ of primer (Operon Technologies). Eighteen $10 \mathrm{bp}$ primers were tested for the process (Operon Technology E-4, 5; I-1, 2, $4,5,6,7,8,9,16,17,18,19,20 ; \mathrm{J}-4,5,16)$. Only those primers that produced high intensity and reproducible bands were used for the remainder of the analyses: I-5, 8, 9,18 , and 19.

Amplifications were conducted in an Eppendorf Mastercycler with a heated lid. Amplifications were initiated for $2 \mathrm{~min}$ at $94^{\circ} \mathrm{C}$, followed by 35 cycles of the following: denaturation at $94^{\circ} \mathrm{C}$ for $2 \mathrm{~min}$, annealing at $37^{\circ} \mathrm{C}$ for $1 \mathrm{~min}$, and elongation at $72^{\circ} \mathrm{C}$ for $2 \mathrm{~min}$. An additional $5 \mathrm{~min}$ at $72^{\circ} \mathrm{C}$ was used to ensure that all amplified products completed their elongation. Amplification products were resolved electrophoretically on a $1.5 \%$ agarose gel and bands were visualized with ethidium bromide fluorescence. Several gels included a PCR control (without DNA) to test for artefactual bands. Samples were assigned randomly to lanes and all gels
Table 2 Oligonucleotide primers and sizes of bands used in analyses

\begin{tabular}{lll}
\hline Primer & Nucleotide sequence & Band sizes (base pairs) \\
\hline OPI-05 & 5'-TGTTCCACGG-3' $^{\prime}$ & $416,819,1300,1790,2270$ \\
OPI-08 & 5'-TTTGCCCGGT-3' $^{\prime}$ & $654,825,895,1110,1310$ \\
OPI-09 & 5'-TGGAGAGCAG-3' $^{\prime}$ & $600,1000,1250,1620,2100$ \\
OPI-18 & 5'-TGCCCAGCCT-3 $^{\prime}$ & $600,660,750,840,1000,1300$, \\
& & $1400,1540,1614,1726$ \\
OPI-19 & 5'-AATGCGGGAG-3' & $693,841,983,1249,1684$ \\
\hline
\end{tabular}

included lanes containing DNA ladders to facilitate standardization. Gels were digitally photographed and the images of multiple gels were standardized using GelCompar software.

\section{Data analysis}

The presence/absence of RAPD bands was recorded in binary format for statistical analysis. The study used only band locations where the presence or absence of the band was clearly identifiable and reproducible in subsequent amplifications: a total of 30 bands from five primers (Table 2). Only samples that were successfully scored for all 30 band locations were used in the statistical analyses.

Genetic variation was estimated using the Shannon Diversity Index (Lewontin, 1972):

Shannon Index: $H=-\sum \mathrm{P}_{i} \times \log _{2}\left(\mathrm{P}_{i}\right)$

where $\mathrm{P}_{i}=$ frequency of the $i$ th band.

Loss of genetic variation manifested by the reduction of rare alleles and the fixation of common ones would be reflected by changes in overall allele frequencies and hence Shannon Index values. Unlike some other studies (eg, Martin and Bermejo, 2000), we did not treat primers as loci and their bands as alleles but instead considered each band location as a locus at which there were two possible alleles: one encoding the presence of the band and the other, its absence. Allele frequencies were obtained by assuming that all RAPD loci exhibit dominance (for the presence of a RAPD band) and follow Hardy-Weinberg equilibrium frequencies. A diversity index was calculated for each locus based on the allele frequencies among all individuals within a given population. The diversity of that population was then calculated by averaging the indices for all 30 loci. Following the convention outlined by Lewontin (1972), genetic variation can be measured at several levels:

$$
\begin{aligned}
& \begin{aligned}
H_{0}= & \text { genetic variation among individuals within } \\
& \text { a population. } \\
H_{\text {pop }}= & \text { average of all populations ' variations }\left(H_{0}\right) \\
& \text { within a group. } \\
H_{\text {groups }}= & \text { genetic variation among all individuals } \\
& \text { within a group. } \\
H_{\text {species }}= & \text { genetic variation among all individuals } \\
& \text { within the species. }
\end{aligned}
\end{aligned}
$$

In this study there were only two groups into which populations were assigned on the basis of forest type: GF or CF. 
In order to evaluate whether fragmentation led to a loss of genetic variation, we subtracted the mean variation of the three GF populations from the mean of the CF populations. The significance of the difference was tested using a nonparametric (Monte Carlo) approach in which we randomly reassigned individuals among populations, after which the difference was recomputed. Repeating the process 1000 times provided a null distribution of values that would occur by chance alone, against which the observed value was compared (Manly, 1998; Schneider et al, 2000).

Genetic differentiation was assessed using a pairwise similarity index within an ANOVA framework to partition diversity within and among populations. Pairwise Euclidean genetic distance measures were calculated and analysed using the analysis of molecular variation (AMOVA) module within Version 2.0 of Arlequin (Schneider et al, 2000). Using our own macro, the equivalent of a posthoc comparison was conducted in order to obtain average among population/within forest type genetic differentiation measures. The similarities of all possible pairs of individuals from different populations within GF sites and within CF sites were calculated using the Sørensen Index (Brower et al, 1998). The mean of the three possible among-site similarities within GF was compared to the mean for those for sites within $\mathrm{CF}$ Spatial autocorrelation was tested by calculating the Pearson's correlation between intersite Sørensen similarities and Euclidean geographical distances. As before, significance values for all relationships were obtained using Monte-Carlo procedures.

\section{Results}

A total of 104 individuals of T. amazonia were successfully scored for all 30 band locations produced by the five primers. A visual assessment of the raw frequencies of the 30 bands indicated that although most bands were present in similar frequencies in the two forest types, some were much less common in GF than in CF sites (eg, bands 4, 5, 6, 20, 21; Figure 2). Conversely, other bands showed minor increases in frequencies in GF populations ( $e g$, bands 8, 18, 23 and 26). No bands were unique to any of the six populations but two GF sites had two

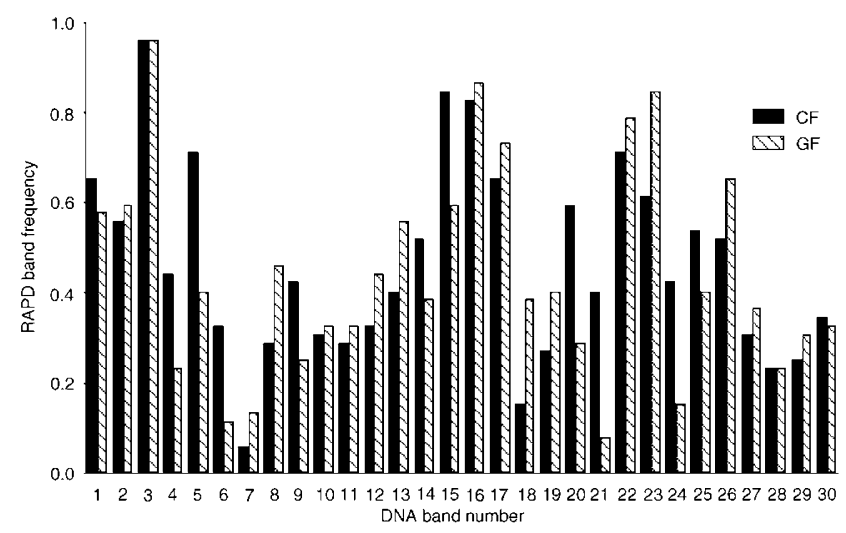

Figure 2 Frequencies of 30 RAPD bands among continuous and gallery forest populations of Terminalia amazonia, in the Mountain Pine Ridge, Belize, amplified using five primers (Operon I-5, 8, 9, 18, 19). Bands were numbered in order of increasing primer number and fragment size (Table 2).
Table 3 Genetic variation of populations of Terminalia amazonia in the Mountain Pine Ridge, Belize, as measured using the Shannon Diversity Index

\begin{tabular}{lcccc}
\hline Site & $\mathrm{H}_{0}$ & $\mathrm{H}_{\text {pop }}$ & $\mathrm{H}_{\text {groups }}$ & $\mathrm{H}_{\text {species }}$ \\
\hline CF1 & 0.383 & & & \\
CF2 & 0.353 & 0.367 & 0.383 & 0.379 \\
CF3 & 0.365 & & & \\
GF1 & 0.346 & & 0.364 & \\
GF2 & 0.322 & 0.349 & & \\
GF3 & 0.378 & & & \\
\hline
\end{tabular}

bands each that were found in juveniles only and not in adults (GF2, bands 6 and 30; GF3, bands 7 and 21). In addition, four bands $(6,7,21$ and 28$)$ were absent from at least one population.

Estimations using the Shannon Index (Lewontin, 1972) indicated that the mean within-population genetic variation of the GF $\left(H_{\text {pop }}=0.349\right.$, Table 3$)$ was slightly but significantly (difference $=0.018, P=0.046$ ) lower than the mean of the CF populations $\left(H_{\text {pop }}=0.367\right)$. A similar loss of variation was apparent when individuals, rather than populations, were grouped by forest type ( $H_{\text {groups }}$, difference $\left.=0.019, P=0.038\right)$. Continuous forest site \#1 had the highest within-population diversity $\left(H_{0}=0.383\right)$, while GF site \#2 had the lowest $\left(H_{0}=0.322\right)$. The overall genetic diversity was 0.379 ( $\left.H_{\text {species }}\right)$.

Analysis of molecular variation showed that the vast majority of the genetic variation of $T$. amazonia was attributable to differences among individuals within populations $(P<0.001$, Table 4$)$. Approximately $4 \%$ could be credited to differences among GF and CF populations but the Monte-Carlo procedure revealed that this figure could be obtained by random placement of individuals among populations $(P=0.100)$. An even smaller proportion $(1.4 \%)$ of variation was produced by differences among populations within the two forest types. Even so, there was a significant $(P<0.001)$ difference in the level of genetic differentiation in the $C F$ and naturally fragmented populations.

Closer examination of genetic variation using Sørensen similarity measures (Table 5) revealed that similarities among GF populations (mean $=0.604$ ) were significantly $(P=0.038)$ higher than among continuous forest populations (mean $=0.584$ ), reflecting a decrease in genetic differentiation in the naturally fragmented populations. Otherwise there seems to be little pattern to intersite similarities. The two sites with the most similar genotypes were GF sites 1 and 2 but the similarities among all other combinations of GF populations and CF populations were comparable. Analysis of spatial autocorrelation found a weak and nonsignificant $\left(R^{2}=0.135\right.$, $P=0.112$ ) correlation between intersite genotype similarity and geographical distance.

\section{Discussion}

RAPD analysis was used to estimate the genetic diversity of CF and naturally fragmented, GF populations of the tropical tree T. amazonia in Belize. The six populations had Shannon index values ranging from 0.32 to 0.38 , with an overall diversity of $0.38\left(H_{\mathrm{spp}}\right)$. These values are 
Table 4 Results from analysis of molecular variance for within and among populations sources of variation for Terminalia amazonia in the Mountain Pine Ridge, Belize

\begin{tabular}{|c|c|c|c|c|c|}
\hline Source of variation & $d f$ & Sums of squares & Variance components & $\%$ of variation & P-values \\
\hline Among forest types & 1 & 21.635 & 0.270 & 4.24 & 0.100 \\
\hline Among populations within forest types & 4 & 30.188 & 0.089 & 1.39 & $<0.001$ \\
\hline Within populations & 98 & 589.658 & 6.017 & 94.37 & $<0.001$ \\
\hline Total & 103 & 641.481 & 6.376 & 100.00 & \\
\hline
\end{tabular}

Table 5 Mean pairwise Sørensen similarity values of genotypes (above diagonal) and geographical distances $(\mathrm{km})$ (below diagonal) between continuous forest and gallery forest populations of Terminalia amazonia in the Mountain Pine Ridge, Belize

\begin{tabular}{lrccccc}
\hline & CF1 & CF2 & CF3 & GF1 & GF2 & GF3 \\
\hline CF1 & - & 0.574 & 0.576 & 0.566 & 0.572 & 0.558 \\
CF2 & 10.54 & - & 0.601 & 0.589 & 0.590 & 0.570 \\
CF3 & 7.95 & 18.32 & - & 0.572 & 0.578 & 0.580 \\
GF1 & 8.38 & 18.68 & 4.74 & - & 0.633 & 0.579 \\
GF2 & 9.42 & 8.27 & 16.65 & 14.86 & - & 0.601 \\
GF3 & 6.85 & 6.68 & 14.51 & 13.43 & 2.93 & -
\end{tabular}

comparable to values published for populations of other tropical tree species, including 0.35 for Swietenia macrophylla (Gillies et al, 1999), 0.45 for Cedrela odorata (Gillies et al, 1997), and 0.59 for Poulsenia armata (Aide and Rivera, 1998). Care should be taken when comparing values across studies because they are influenced by the genetic markers employed and because of inconsistent methods of calculating diversity (eg, Gillies et al, 1999; Martin and Bermejo, 2000).

The analysis of molecular variation revealed that the vast majority (94\%) of the molecular variance recorded in T. amazonia in the MPR was attributable to differences among individuals within the populations. Low levels of population differentiation are common in tropical tree species at small spatial scales (Hamrick and Loveless, 1989). For example, a study in Costa Rica found that more than $96 \%$ of the genetic variation in Dendropanax arboreus, Inga thibaudiana, and Protium glabrum was attributable to differences within plots along a $9 \mathrm{~km}$ transect (Schierenbeck et al, 1997). However, population differentiation does tend to rise with increasing distances between populations and may be exacerbated by forest fragmentation (Hall et al, 1996; Aide and Rivera, 1998; Gillies et al, 1999).

Most research investigating the effect of forest fragmentation on the genetic diversity of tropical trees has been conducted in recently disturbed landscapes in which ecological processes have had little time to adjust to the altered environment (eg, Hall et al, 1996; Aldrich et al, 1998; Dick, 2001). To the best of our knowledge, only one other researcher has utilized natural forest fragments to predict the long-term genetic consequences of fragmentation on tropical trees (Shapcott, 1998, 1999, 2000). That project concluded that isolated populations of Carpentaria acuminata were effectively inbred and had low genetic diversity, while Syzygium nervosum had maintained high levels of genetic diversity regardless of population size or isolation (Shapcott, 2000).
In the MPR, we found that GF populations of $T$. amazonia had slightly, but statistically significant $(P=0.046)$ lower levels of genetic variation than those of nearby continuous forest populations, indicating that the long-term fragmentation has had a negative effect on genetic diversity. Theory suggests that random processes in fragmented and isolated populations could lead to a decline in the frequency of rare alleles and an increase in common ones (Young et al, 1996; White et al, 2002). However, evidence provided by the raw frequencies of the 30 DNA bands generated in this study does not reflect that expectation since the bands that experienced dramatic changes in frequencies were not rare nor common ones.

Interestingly, while two of three GF populations had the lowest variation of all six sites, the other fragmented population (GF3) actually had a higher level of diversity than two of the CF populations. This difference in genetic variance appears to be matched by a difference in local GF cover. Both genetically depauperate sites had very little local forest cover with less than 1 ha within a $1.5 \mathrm{~km}$ radius each. The relatively genetically diverse GF3, on the other hand, had more than 10 ha of gallery forest within the same radius. This limited data raises the possibility of a landscape effect in which local forest cover is affecting gene flow, most likely via impacts on pollinator movement. Although some seed and pollen dispersers are undeterred by nonforested habitat and continue to move among forest remnants (Estrada et al, 1993; Dick, 2001), other dispersers appear to be reluctant to cross even small breaks between forest fragments (Powell and Powell, 1987). In the MPR, the limited forest cover surrounding the two GF sites with low genetic variation must have provided an insufficient degree of connectivity to facilitate visits from pollinators.

Landscape composition provides a plausible explanation for differences in genetic variation among the GF populations, but it cannot explain why site GF3 had a higher level of variation than two of the CF sites. The data suggest that somehow, of those three sites, the fragmented one had experienced the highest amount of gene flow. Other studies have found evidence of increased pollen flow following forest fragmentation, including for the tropical tree species Spondias mombin (Nason and Hamrick, 1997) and Swietenia humilis (White et al, 2002), as well as for the temperate species Acer saccharum (Young et al, 1993). White et al (2002) went as far as to suggest that over time, increased gene flow arising from forest fragmentation could eventually augment levels of genetic variation. But given that two of the GF sites in the MPR had low levels of variation, there is likely a threshold of local forest cover required to facilitate increased gene flow after forest fragmentation, below which populations will experience 
reduced gene flow and consequently the expected loss of genetic diversity.

Forest fragmentation is also expected to lead to an increase in interpopulation genetic differentiation as a result of random genetic drift (Young et al, 1996; Dayanadan et al, 1999). However, we found the opposite for T. amazonia in the MPR, with significantly $(P=0.038)$ lower levels of differentiation (higher levels of similarity) among GF populations than among CF populations. Young et al (1993) recorded a similar result for $A$. saccharum, which they attributed to an increase in gene flow among forest fragments. That explanation would not be consistent with our data since the two most isolated populations with the lowest genetic variation (GF1 and GF2) were also the most similar of all possible pairs of sites.

In summary, results from this study suggest that the long-term fragmentation of populations of T. amazonia in the MPR has, on average, had a negative effect on the genetic diversity of the species. However, variation in diversity among the sites indicates a potential landscape effect in which local forest cover may have determined the outcome. Although limited, our data suggest that sites with sufficient cover may acquire higher levels of genetic diversity, possibly as a result of increased gene flow, while populations in sites with forest cover below a certain threshold would experience the expected decline in genetic diversity. Further research is required to test this hypothesis. The results from this study complement other research attempting to evaluate the effect of forest loss and fragmentation on the genetic diversity of tropical trees (eg, Hall et al, 1996; Aldrich et al, 1998; Dayanandan et al, 1999; Dick, 2001; White et al, 2002). At this point it is difficult to identify generalities because results from the few studies conducted thus far have not been consistent, even from those utilizing natural and potentially ancient forest fragments (Shapcott, 1998, 2000). Ultimately, it is likely that the effect of fragmentation will be species specific and will depend on each species' reproductive biology and in particular the response of their pollen and seed dispersal vectors to the modified landscape.

\section{Acknowledgements}

We are grateful to the Belize Forestry Department for providing permission to work in the Mountain Pine Ridge and for logistical support in the field. We thank A Howe for invaluable field assistance, $\mathrm{K}$ Tao and J Krzyzanowski for dedicated lab work, R Fulthorpe for the use of GelCompar software, A Gillies for technical advice, and S Truyens, D Khosravi and F Tamari for general assistance and patience. Research was supported by financial grants from the Natural Sciences and Engineering Council of Canada to MK \& JS, and from the Government of Ontario and York University to RP We also thank two anonymous reviewers whose comments helped to improve this manuscript.

\section{References}

Aide TM, Rivera E (1998). Geographic patterns of genetic diversity in Poulsenia armata (Moraceae): implications for the theory of Pleistocene refugia and the importance of riparian forest. J Biog 25: 695-705.
Aldrich PR, Hamrick JL, Chavarriaga P, Kochert G (1998). Microsatellite analysis of demographic genetic structure in fragmented populations of the tropical tree. Symphonia globulifera Mol Ecol 7: 933-944.

Brower JE, Zar JH, von Ende CN (1998). Field and Laboratory Methods for General Ecology. WCB McGraw-Hill: New York.

Condit R, Sukumar R, Hubbell SP, Foster RB (1998). Predicting population trends from size distributions: a direct test in a tropical tree community. Am Nat 152: 495-509.

Dayanandan S, Dole J, Bawa K, Kesseli R (1999). Population structure delineated with microsatellite markers in fragmented populations of a tropical tree, Carapa guianensis (Meliaceae). Mol Ecol 8: 1585-1592.

Dick CW (2001). Genetic rescue of remnant tropical trees by an alien pollinator. Proc Roy Soc Lond B 268: 2391-2396.

Doyle JJ, Doyle J (1987). A rapid DNA isolation procedure for small quantities of fresh leaf tissue. Phytochem Bull, 19: 11-15.

Estrada A, Coates-Estrada R, Meritt Jr D, Curiel D (1993). Patterns of frugivore species richness and abundance in forest islands and in agricultural habitats at Los Tuxtlas, Mexico. Vegetatio 107/108: 245-257.

Frankel OH, Soulé ME (1981). Conservation and Evolution. Cambridge University Press: Cambridge.

Gentry AH (1993). A Field Guide to the Families and Genera of Woody Plants of Northwest South America. University of Chicago Press: Chicago.

Gillies ACM, Cornelius JP, Newton AC, Navarro C, Hernandez M, Wilson J (1997). Genetic variation in Costa Rican populations of the tropical timer species Cedrela odorata L., assessed using RAPDs. Mol Ecol 6: 1133-1145.

Gillies ACM, Navarro C, Lowe AJ, Newton AC, Hernandez M, Wilson J, Cornelius JP (1999). Genetic diversity in Mesoamerican populations of mahogany (Swietenia macrophylla), assessed using RAPDs. Heredity 83: 722-732.

Hall P, Walker S, Bawa K (1996). Effect of forest fragmentation on genetic diversity and mating system in a tropical tree. Pithecellobium elegans Conserv Biol 10: 757-768.

Hamrick JL, Loveless MD (1989). The genetic structure of tropical tree populations: associations with reproductive biology. In: Bock JH, Lindhart YB (eds) Evolutionary Ecology of Plants, Westview Press: Boulder, CO, pp 129-146.

Hamrick JL, Murawski DA, Nason JD (1993). The influence of seed dispersal mechanisms on the genetic structure of tropical tree populations. In: Fleming TH, Estrada A (eds) Frugivory and Seed Dispersal: Ecological and Evolutionary Aspects,. Kluwer Academic Publishers: Dordrecht, the Netherlands, pp 281-298.

Kellman M (1989). Mineral nutrient dynamics during savannaforest transformation in Central America. In: Proctor J (ed) Mineral Nutrients in Tropical Forest and Savanna Ecosystems, Blackwell Scientific Publications: Oxford, pp 137-151.

Kellman M (1996). Redefining roles: plant community reorganization and species preservation in fragmented systems. Global Ecol Biog Lett 5: 111-116.

Kellman M, Miyanishi K (1982). Forest seedling establishment in Neotropical savannas: observations and experiments in the Mountain Pine Ridge savanna, Belize. J Biog 9: 193-206.

Lewontin RC (1972). The apportionment of human diversity. Evol Biol 6: 381-398.

Manly BFJ (1998). Randomization, Bootstrap and Monte Carlo methods in Biology. Chapman \& Hall: London.

Martin JP, Bermejo JEH (2000). Genetic variation in the endemic and endangered Rosmarinus tomentosus Huber-Morath \& Maire (Labiatae) using RAPD markers. Heredity 85: 434-443.

Meave J, Kellman M (1994). Maintenance of rain forest diversity in riparian forests of tropical savannas: implications for species conservation during Pleistocene drought. J Biog 21: 121-135.

Myers N (1986). Tropical deforestation and a mega-extinction spasm. In: Soulé M.E. (ed) Conservation Biology: The Science of 
Scarcity and Diversity, Sinauer Associates: Sunderland, pp 394-409.

Nason JD, Hamrick JL (1997). Reproductive and genetic consequences of forest fragmentation: two cases of neotropical canopy trees. J Hered 88: 264-276.

Ohri D (1996). Genome size and polyploidy variation in the tropical genus Terminalia (Combretaceae). Plant Syst Evol 200: 225-232.

Pither R, Kellman M (2002). Tree species diversity in small, tropical riparian forest fragments in Belize, Central America. Biod Conserv 11: 1623-1636.

Powell AH, Powell GVN (1987). Population dynamics of male Euglossine bees in Amazonian forest fragments. Biotropica 19: 176-179.

Schierenbeck KA, Skupski M, Lieberman D, Lieberman M (1997). Population structure and genetic diversity in four tropical tree species in Costa Rica. Mol Ecol 6: 137144.

Schneider S, Roessli D, Excoffier L (2000). Arlequin ver. 2.0: a Software for Population Genetics data Analysis. Genetics and Biometry Laboratory, University of Geneva, Switzerland.

Shapcott A (1998). Vagile but inbred: patterns of inbreeding and the genetic structure within populations of the monsoon rain forest tree Syzygium nervosum (Myrtaceae) in northern Australia. J Trop Ecol 14: 595-614.
Shapcott A (1999). Vagility and the monsoon rain forest archipelago of northern Australia: patterns of genetic diversity in Syzygium nervosum (Myrtaceae). Biotropica 31: 579-590.

Shapcott A (2000). Conservation and genetics in the fragmented monsoon rainforest in the Northern Territory, Australia: a case study of three frugivore-dispersed species. Aust J Bot 48: 397-407.

Srivastav PK, Ranjan P, Sinha SS (1993). Conservation of Terminalia genetic resources: the principal source of nonwood products in India. For Gen Resources 24: 1-6.

Standley PC (1962). Flora of Guatemala. Fieldiana: Botany 24 278-279.

Taylor PD, Fahrig L, Henein K, Merriam G (1993). Connectivity is a vital element of landscape structure. Oikos 68: 571-573.

White GM, Boshier DH, Powell W (2002). Increased pollen flow counteracts fragmentation in a tropical dry forest: an example from Swietenia humilis Zuccarini. Proc Natl Acad Sci USA 99: 2038-2042.

Young A, Boyle T, Brown T (1996). The population genetic consequences of habitat fragmentation for plants. Trends Ecol Evol 11: 413-418.

Young AG, Merriam G, Warwick SI (1993). The effects of forest fragmentation on genetic variation in Acer saccharum Marsh. (sugar maple) populations. Heredity 71: 277-289. 